Research article

\title{
Classification of ductal carcinoma in situ by gene expression profiling
}

\author{
Juliane Hannemann ${ }^{1}$, Arno Velds ${ }^{2}$, Johannes BG Halfwerk¹, Bas Kreike ${ }^{1,3}$, Johannes L Peterse ${ }^{4}$ \\ and Marc J van de Vijver 1,4
}

\begin{abstract}
1Division of Experimental Therapy, Netherlands Cancer Institute, Plesmanlaan 121, 1066 CX Amsterdam, The Netherlands
${ }^{2}$ Central Microarray Facility, Netherlands Cancer Institute, Plesmanlaan 121, 1066 CX Amsterdam, The Netherlands

${ }^{3}$ Division of Radiotherapy, Netherlands Cancer Institute, Plesmanlaan 121, 1066 CX Amsterdam, The Netherlands

${ }^{4}$ Division of Diagnostic Oncology, Netherlands Cancer Institute, Plesmanlaan 121, 1066 CX Amsterdam, The Netherlands
\end{abstract}

Corresponding author: Marc J van de Vijver, m.vd.vijver@nki.nl

Received: 19 Jul 2006 Revisions requested: 22 Aug 2006 Revisions received: 25 Sep 2006 Accepted: 30 Oct 2006 Published: 30 Oct 2006

Breast Cancer Research 2006, 8:R61 (doi:10.1186/bcr1613)

This article is online at: http://breast-cancer-research.com/content/8/5/R61

(c) 2006 Hannemann et al.; licensee BioMed Central Ltd.

This is an open access article distributed under the terms of the Creative Commons Attribution License (http://creativecommons.org/licenses/by/2.0), which permits unrestricted use, distribution, and reproduction in any medium, provided the original work is properly cited.

\begin{abstract}
Introduction Ductal carcinoma in situ (DCIS) is characterised by the intraductal proliferation of malignant epithelial cells. Several histological classification systems have been developed, but assessing the histological type/grade of DCIS lesions is still challenging, making treatment decisions based on these features difficult. To obtain insight in the molecular basis of the development of different types of DCIS and its progression to invasive breast cancer, we have studied differences in gene expression between different types of DCIS and between DCIS and invasive breast carcinomas.
\end{abstract}

Methods Gene expression profiling using microarray analysis has been performed on 40 in situ and 40 invasive breast cancer cases.
Results DCIS cases were classified as well- $(n=6)$, intermediately ( $n=18)$, and poorly $(n=14)$ differentiated type. Of the 40 invasive breast cancer samples, five samples were grade I, 11 samples were grade II, and 24 samples were grade III. Using two-dimensional hierarchical clustering, the basal-like type, ERB-B2 type, and the luminal-type tumours originally described for invasive breast cancer could also be identified in DCIS.

Conclusion Using supervised classification, we identified a gene expression classifier of 35 genes, which differed between DCIS and invasive breast cancer; a classifier of 43 genes could be identified separating between well- and poorly differentiated DCIS samples.

\section{Introduction}

Ductal carcinoma in situ (DCIS) of the breast represents a heterogeneous group of non-invasive breast tumours commonly detected in women undergoing screening mammography. $\mathrm{DCIS}$ is characterised by malignant epithelial cells accumulating in the ducts of the breast without invading through the basement membrane into the surrounding tissue. DCIS accounts for approximately $3 \%$ of symptomatic breast malignancies and for approximately $20 \%$ of breast malignancies in patients from population-based screening programs [1].

Different histological types of DCIS can be recognised, and a variety of classification systems have been developed [2]. Due to subjective interpretation of the morphology of the lesions, even experienced pathologists differ in their classification of DCIS [3]. Therefore, histological classification of DCIS may not be sufficient, and additional classification approaches could assist pathological classification.

It is assumed that most cases of DCIS will progress to invasive breast cancer. Because this progression may take many years and may not occur within the lifetime of a patient, elucidating the mechanisms of progression from in situ lesions to invasive disease and developing diagnostic tests would be of great clinical benefit.

Several models of the evolution of DCIS to invasive cancer have been suggested. One model suggests the linear progression from low-nuclear-grade DCIS to high-nuclear DCIS and 
the subsequent development of invasive cancer [4]. Based on specific genetic alterations found in the different types of DCIS, a more likely scenario is the evolution of well-, moderately, and poorly differentiated DCIS via distinct pathways. Following this idea, well-differentiated DCIS can give rise to lowgrade invasive carcinoma, whereas poorly differentiated DCIS can give rise to high-grade invasive breast cancer $[5,6]$.

Several specific genetic alterations have been found in DCIS. HER2 gene amplification and protein overexpression are detected in up to $70 \%$ of poorly differentiated DCIS cases [7], and cyclin D1 is amplified and overexpressed in DCIS [8] in approximately $20 \%$ of the cases. Inactivating mutations of the E-cadherin gene are detected in almost all cases of lobular carcinoma in situ (LCIS) [9]. Several other genetic alterations in oncogenes (for example, C-MYC) and tumour suppressor genes (for example, p53) have been found in DCIS and are reviewed in Reis-Filho and colleagues [10] and Allred and colleagues [11].

Gene expression profiling has been shown to be a powerful tool for identifying profiles of tumour subtypes [12-15] and for correlating gene expression profiles with outcome in breast cancer [16-18]. The identification of specific gene expression patterns correlated with the different types of DCIS may help to elucidate the processes underlying the evolution of in situ carcinomas of the breast and also lead to a more reproducible classification of DCIS lesions.

To date, only a few studies of gene expression profiling of DCIS and a comparison with the gene expression pattern of invasive samples have been published and these are based on a small number of samples $[19,20]$.

In the study presented here, gene expression profiling was performed on one LCIS and 39 DCIS samples to identify differentially expressed genes between well-, intermediately, and poorly differentiated DCIS. In addition, differences in gene expression between these cases of carcinoma in situ and 40 invasive breast carcinomas were studied.

\section{Materials and methods Selection of samples}

Cases of DCIS were selected from the tissue bank of the Netherlands Cancer Institute (Amsterdam, The Netherlands). These samples were obtained within 1 hour after surgery from patients who underwent wide local excision $(n=16)$ or mastectomy $(n=24)$. All samples were reviewed by two pathologists independently to determine the histological classification of the samples according to Holland and colleagues [21]; samples were classified as well, intermediately, or poorly differentiated. For analysis purposes, the intermediately differentiated DCIS cases were subclassified as those cases that were in part well differentiated (well to intermediately differentiated) and those that were in part poorly differentiated (mod- erately to poorly differentiated) in some areas. In cases in which there was a discrepancy in classification between the two pathologists, the histological slides were reviewed together to reach an agreement.

In addition, 40 cases of primary invasive breast cancer were selected; these were all cases of invasive ductal carcinoma (IDC) measuring between 1 and $5 \mathrm{~cm}$ and were graded as grade 1, 2, or 3 according to the method described by Elston and Ellis [22]. The study was approved by the medical ethical committee of the Netherlands Cancer Institute.

\section{RNA isolation and amplification}

RNA isolation and amplification were performed essentially as described by Weigelt and colleagues [23]. Thirty tissue sections of $30 \mu \mathrm{m}$ of frozen material were cut. The first and the last tissue sections were $6 \mu \mathrm{m}$ in thickness and were stained with haematoxylin and eosin to determine the percentage of tumour cells and to exclude invasive growth. Only samples with greater than or equal to $50 \%$ of tumour cells were used for gene expression profiling.

\section{Immunohistochemistry}

The procedures applied are described in the supplementary information provided online [24].

\section{Microarray hybridisation}

Labeling of the amplified cRNA and microarray hybridisations were performed as previously described [25]. Equal amounts of amplified cRNAs of 100 invasive breast carcinomas were pooled and used as a reference. All hybridisations were performed on $18 \mathrm{~K}$ human cDNA arrays (Central Microarray Facility, Netherlands Cancer Institute) [26].

Microarrays were scanned with the DNA Microarray Scanner G2565B (Agilent Technologies, Santa Clara, CA, USA). Selfself hybridisations were used to validate the quality of the hybridisations and as a negative control in the error model.

\section{Processing of microarray data}

Information on data processing is provided in the supplementary information [24].

\section{Unsupervised hierarchical clustering}

Two-dimensional unsupervised hierarchical clustering using Pearson correlation as distance function and complete linkage was performed using Genesis software (Technical University, Graz, Austria) $[27,28]$.

\section{Supervised classification}

We performed supervised classification applying methods described previously $[16,29,30]$. Pathological features (histological type of the DCIS samples, histological grade of the invasive samples) were used to define groups for supervised classification. Genes were rank-ordered based on their signal- 
to-noise statistic. Safe cutoffs were determined by comparing the signal-to-noise ratio (SNR) values with the results from 2,000 sample label permutations (Monte Carlo randomisation). For each group and a number of genes, a centroid is defined as the mean ratio per gene over all samples in that group. Correlation or Euclidean distance of each sample to those centroids determines their predicted group. Leave-out cross-validation was used to determine the optimal number of genes separating the groups. The number of left-out samples in this cross-validation procedure was dependent on the number of samples within the analysis set. SNR calculation, Monte Carlo randomisation, and cross-validation have been described previously [25].

\section{Supplementary information}

The microarray data, additional information on the methods, and the filtering results are provided as supplementary information [24].

\section{Results}

This study was performed to identify differences in gene expression (a) between DCIS and invasive breast cancer and (b) between different histological types of DCIS.

\section{Tumour characteristics}

Thirty-nine cases of DCIS of the breast were included in the analyses. By histological examination, they were assigned to the following groups: well differentiated $(n=6)$, intermediately differentiated $(n=18)$, and poorly differentiated $(n=14)$. For analysis purposes, the group of intermediately differentiated cases was further subdivided in well-intermediately $(n=10)$, true intermediately $(n=2)$, and intermediately-poorly $(n=6)$ differentiated type. One sample contains a mixture of well- and poorly differentiated DCIS components in the same tissue specimen. In addition, one case of LCIS was included.

To be able to compare DCIS with invasive breast cancer, 40 cases of invasive breast cancer were studied. Five tumours were histological grade 1, 11 samples were grade 2, and 24 samples were grade 3 . Patient and tumour characteristics are summarised in Table 1.

\section{Molecular subtypes of breast cancer}

Several subtypes of breast cancer have been identified by gene expression profiling and have been correlated with clinical outcome [13,14]. This classification has been translated to classical immunohistochemistry (IHC): basal-type tumours are characterised by negative staining for oestrogen receptor (ER), progesterone receptor, and HER2 and are often positive for keratin 5/6; ERB-B2 tumours are HER2-positive, and luminal $A$ and $B$ tumours are ER-positive and HER2-negative. In our set of 40 in situ tumours, only two tumours are positive for CK5/6 by IHC. Both of them are poorly differentiated and negative for HER2 and ER by IHC. From the intrinsic gene set identified by Perou and colleagues [12], we could match 403 identifiers to our array platform. This set of genes was used to perform unsupervised hierarchical clustering of the 40 in situ samples. We clearly see a discrimination between tumours highly expressing genes of the luminal/ESR1 cluster and tumours negative for these genes, whereas the discrimination for the HER2-overexpressing groups was much less clear (Figure 1 in the supplementary information [24]). We could not identify a large basal-type group, which is in agreement with the data obtained using $\mathrm{IHC}$.

\section{Unsupervised hierarchical clustering}

Unsupervised hierarchical clustering of in situ and invasive samples

First, the whole group of DCIS and invasive samples was clustered (Figure 1a). As can be seen, the invasive samples cluster in three different groups (indicated as I, II, and III in Figure 1a). Ten out of 14 poorly differentiated DCIS samples cluster together in a fourth group, and a fifth group consists of 13 out of 18 cases of intermediately differentiated DCIS and four out of six of the well-differentiated in situ samples. The clustering seems not to be driven mainly by the ER status or the HER2 status of the samples. These results suggest that poorly differentiated DCIS samples show an overall gene expression profile other than that of the intermediately and well-differentiated DCIS samples.

\section{Unsupervised hierarchical clustering of DCIS}

We also performed unsupervised hierarchical cluster analysis to the series of DCIS cases only, resulting in two large groups. One group contains 10 poorly differentiated samples and only one well-differentiated sample, whereas $83 \%$ of the well-differentiated samples group in the other, second cluster. Most of the samples in this second group are ER-positive by IHC. In total, our sample set contains 18 cases with an intermediately differentiated component. Of these samples, 12 cluster in the arm of the well-differentiated samples. In accordance with the clustering results presented in Figure 1, these results also indicate that the overall gene expression profiles of in situ samples with an intermediately differentiated component are more similar to those of well-differentiated DCIS than to those of poorly differentiated DCIS. It is clear from these results that there are large differences in gene expression pattern between welland poorly differentiated DCIS.

\section{Supervised classification}

We performed supervised classification on different data sets to identify the genes differentially expressed between the groups of interest. These groups are (a) 40 in situ versus 40 invasive breast carcinomas, (b) 14 poorly differentiated DCIS cases versus 38 invasive grade 3 tumours, and (c) six cases of well-versus 14 cases of poorly differentiated DCIS. 
Breast Cancer Research Vol 8 No 5 Hannemann et al.

Table 1

\begin{tabular}{|c|c|c|c|}
\hline In situ samples & & Invasive samples & \\
\hline Differentiation & Number (percentage) & Histological grade & Number (percentage) \\
\hline Well & $6(15 \%)$ & 1 & $5(12.5 \%)$ \\
\hline Intermediately & $18(45 \%)$ & 2 & $11(27.5 \%)$ \\
\hline Poorly & $14(35 \%)$ & 3 & $24(60 \%)$ \\
\hline Good/poor component & $1(2.5 \%)$ & & \\
\hline LCIS & $1(2.5 \%)$ & & \\
\hline $\mathrm{IHC}$ & & $\mathrm{IHC}$ & \\
\hline ER-positive & $28(70 \%)^{a}$ & ER-positive & $22(55 \%)^{c}$ \\
\hline PR-positive & $24(60 \%)^{a}$ & PR-positive & $19(47.5 \%)^{d}$ \\
\hline Her2/neu-positive (3+) & $12(30 \%)^{b}$ & Her2/neu-positive $(3+)$ & $4(10 \%) d$ \\
\hline p53-positive & $11(27.5 \%)^{b}$ & p53-positive & $9(22.5 \%)^{d}$ \\
\hline \multicolumn{4}{|l|}{ Tumour detection } \\
\hline Palpation & $17(42.5 \%)$ & & \\
\hline Microcalcifications & $18(45 \%)$ & & \\
\hline Others & $5(12.5 \%)$ & & \\
\hline \multicolumn{4}{|l|}{ Tumour diameter (mm) } \\
\hline Range & 10 to 80 & & \\
\hline Median & 45 & & \\
\hline Average & 42.8 & & \\
\hline \multicolumn{4}{|l|}{ Treatment } \\
\hline Mastectomy & $24(60 \%)$ & & \\
\hline Breast conserving treatment & $6(15 \%)$ & & \\
\hline $\begin{array}{l}\text { Local excision followed by } \\
\text { mastectomy }\end{array}$ & $10(25 \%)$ & & \\
\hline
\end{tabular}

a5\% not assessable, ${ }^{b} 2.5 \%$ not assessable, ${ }^{c} 27.5 \%$ not assessable, ${ }^{d} 30 \%$ not assessable. ER, oestrogen receptor; IHC, immunohistochemistry; LCIS, lobular carcinoma in situ; PR, progesterone receptor.

Supervised classification of in situ versus invasive carcinomas

We investigated the differences in gene expression between in situ and invasive breast carcinoma samples. We therefore used the whole data set and assigned all 40 in situ samples to one group and all 40 invasive samples to a second group (analysis set 1). To obtain a profile taking into account the expression sets of both tumour types, significantly regulated genes were identified independently for both groups. The 1,706 overlapping genes were used for analysis. Monte Carlo randomisation revealed approximately 300 genes differentially expressed between in situ and invasive samples.

After cross-validation, classifier consisting of 35 genes resulted in a stable prediction of the differences between DCIS and invasive breast carcinomas, with an average performance of $91 \%$. The gene list is provided in Table 2 .
Supervised classification for poorly differentiated DCIS versus grade 3 invasive carcinoma

Because it is very likely that grade 3 invasive breast cancer arises from poorly differentiated DCIS [5,6], we applied the supervised classification procedure to the subset of poorly differentiated DCIS $(n=14)$ and grade 3 invasive tumours ( $n=$ 24) (analysis set 2). Again, the filtering procedure was applied to both groups independently. The overlapping fraction of this gene list contains 1,119 genes that were used to perform the analyses. Monte Carlo randomisation showed that 80 genes are differentially expressed between poorly differentiated DCIS and grade 3 invasive breast carcinoma samples. After cross-validation in 14 steps, the best performance of $93 \%$ is reached, when at least 50 genes are used to build the classifier. This performance remains stable with increasing numbers of genes. This means that 50 to 80 genes are able to discriminate between poorly differentiated DCIS and invasive grade 3 
(a)

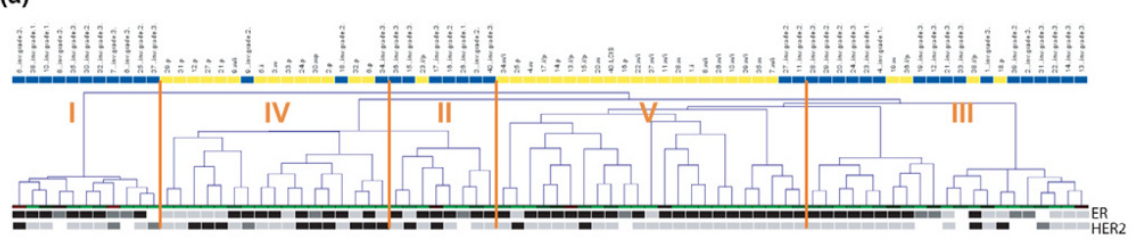

(b)

(c)

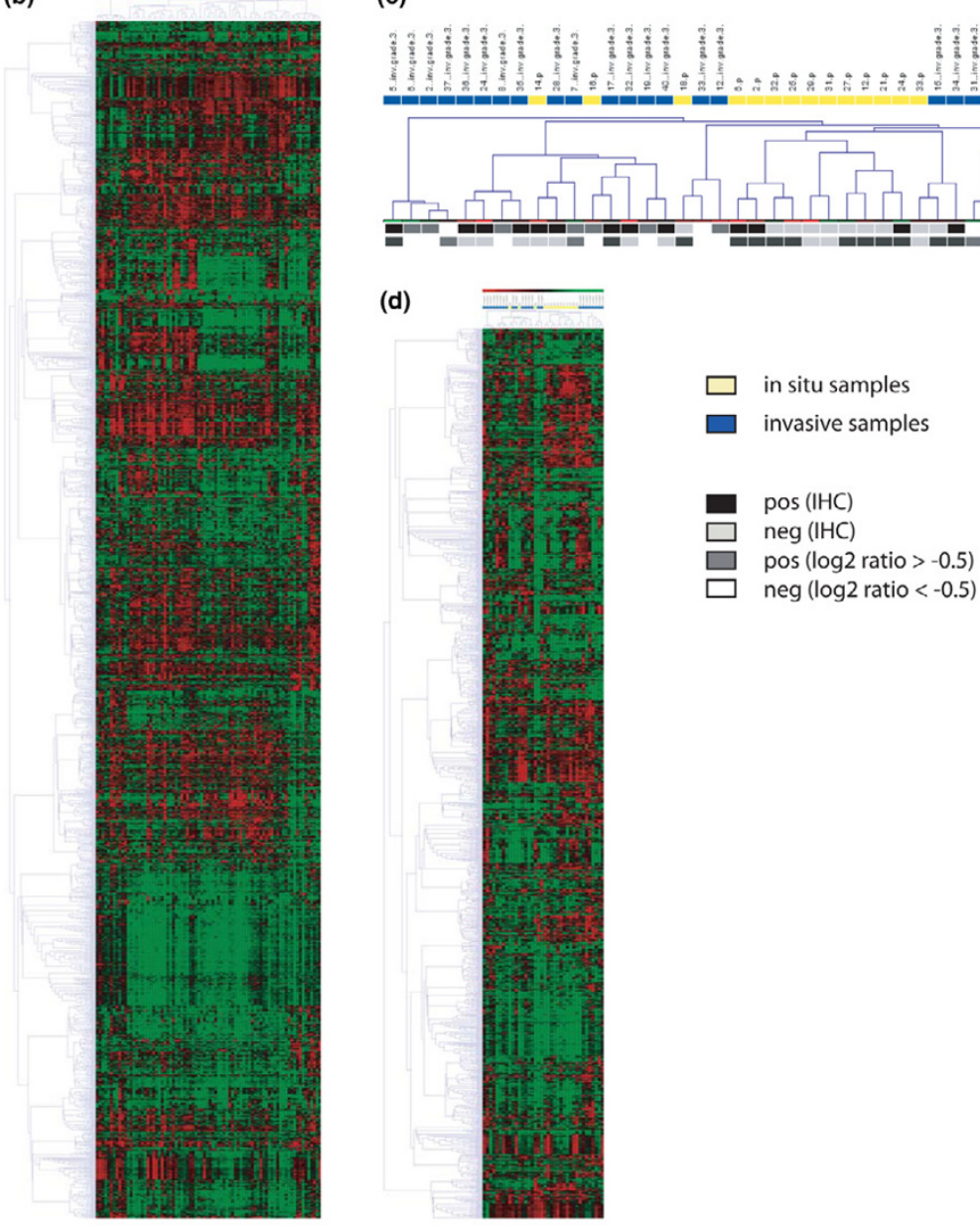

Unsupervised hierarchical clustering of in situ and invasive samples. (a) Dendrogram of all in situ $(n=40)$ and all invasive $(n=40)$ samples. (b) Scaled-down representation of the entire cluster shown in (a) (1,706 genes). (c) Dendogram of poorly differentiated ductal carcinoma in situ ( $n=$ 14) and grade 3 invasive $(n=24)$ samples. (d) Entire cluster of (c) (1,119 genes). Yellow indicates in situ samples, and blue indicates invasive samples. i, intermediately differentiated; IHC, immunohistochemistry; i/p, intermediately/poorly differentiated; LCIS, lobular carcinoma in situ; p, poorly differentiated; $w$, well differentiated; w/i, well/intermediately differentiated.

breast tumours (Figure 2a). These 80 genes are shown in Table 3. Between the 35-gene classifier of all DCIS and invasive samples and the subgroup classifier of 80 genes, 21 genes were present in both classifiers.

\section{Supervised classification of well-versus poorly differentiated DCIS}

We intended to find the most prominent differences between the well- and poorly differentiated DCIS samples. Sixfold cross-validation of six well- and 14 poorly differentiated in situ samples (analysis set 3 ) resulted in a set of 43 genes separating these groups with a performance of $90 \%$ (Figure 3a, Table 4).

Because histological classification of intermediately differentiated DCIS versus well- or moderately differentiated DCIS is most challenging, we investigated whether gene expression profiling could be used to identify markers that could help in 
Breast Cancer Research Vol 8 No 5 Hannemann et al.

Table 2

List of $\mathbf{3 5}$ genes able to discriminate between all DCIS and all invasive samples

\begin{tabular}{|c|c|c|c|c|}
\hline Rank & NKI ID & Symbol & Annotation & Accession no. \\
\hline 1 & 116810 & $A D M$ & Adrenomedullin & AA446120 \\
\hline 2 & 123346 & & EST & H17315 \\
\hline 3 & 117289 & MMP11 & Matrix metalloproteinase 11 (stromelysin 3) & AA045500 \\
\hline 4 & 121066 & $D A P K 3$ & Death-associated protein kinase 3 & AA973730 \\
\hline 5 & 123776 & PIAS4 & Protein inhibitor of activated STAT protein & Н30547 \\
\hline 6 & 101837 & DHX34 & KIAA0134 gene product & AA477623 \\
\hline 7 & 102847 & YIF1 & Putative transmembrane protein; homolog of yeast Golgi membrane protein Yif1p (Yip1p-interacting factor) & $\mathrm{H} 79351$ \\
\hline 8 & 117345 & ACTN1 & Actinin, alpha 1 & AA669042 \\
\hline 9 & 127755 & TGFB2 & Transforming growth factor, beta 2 & W47556 \\
\hline 10 & 108960 & $G A B R D$ & Gamma-aminobutyric acid (GABA) A receptor, delta & $\mathrm{H} 41122$ \\
\hline 11 & 108348 & MFAP2 & Microfibrillar-associated protein 2 & N67487 \\
\hline 12 & 129658 & MGC13045 & DnaJ (Hsp40) homolog, subfamily C, member 4 & AA996059 \\
\hline 13 & 105479 & BAT3 & HLA-B-associated transcript-3 & AA434416 \\
\hline 14 & 120649 & KCTD5 & Hypothetical protein & AA521027 \\
\hline 15 & 110728 & $F B X L 15$ & F-box and leucine-rich repeat protein 15 & T61547 \\
\hline 16 & 120934 & EIF4G1 & Eukaryotic translation initiation factor 4 gamma, 1 & R37276 \\
\hline 17 & 118584 & C9orf115 & ESTs, weakly similar to B36298 proline-rich protein PRB3S [Homo sapiens] & AA479713 \\
\hline 18 & 105533 & ARF1 & ADP-ribosylation factor 1 & W45572 \\
\hline 19 & 131909 & TUBB2 & Tubulin, beta polypeptide & Al672565 \\
\hline 20 & 131540 & PRPF31 & DKFZP566J153 protein & Al253017 \\
\hline 21 & 110281 & HSPA1L & Heat shock $70-\mathrm{kD}$ protein-like 1 & H17513 \\
\hline 22 & 107215 & KCTD5 & Hypothetical protein & AA429470 \\
\hline 23 & 121937 & FLJ10374 & Hypothetical protein FLJ10374 & AA676962 \\
\hline 24 & 100368 & GNB2 & Guanine nucleotide binding protein ( $G$ protein), beta polypeptide 2 & N68166 \\
\hline 25 & 105453 & PSAP & Prosaposin (variant Gaucher disease and variant metachromatic leukodystrophy) & N72215 \\
\hline 26 & 115391 & $L M C D 1$ & LIM and cysteine-rich domains 1 & AA452125 \\
\hline 27 & 128198 & MMP11 & Matrix metalloproteinase 11 (stromelysin 3) & AA954935 \\
\hline 28 & 123688 & COL1A1 & Collagen, type I, alpha 1 & R48844 \\
\hline 29 & 127890 & PTMS & Parathymosin & AA458981 \\
\hline 30 & 102044 & $D R A P 1$ & DR1-associated protein 1 (negative cofactor 2 alpha) & AA406285 \\
\hline 31 & 101067 & MAP7 & Microtubule-associated protein 7 & R77252 | R77251 \\
\hline 32 & 129438 & IQGAP1 & IQ motif containing GTPase activating protein 1 & AA478633 \\
\hline 33 & 125700 & APC2 & Adenomatous polyposis coli like & AA976241 \\
\hline 34 & 127881 & NFIC & Nuclear factor I/C (CCAAT-binding transcription factor) & T59427 \\
\hline 35 & 109065 & SYT5 & Synaptotagmin V & Н39018 \\
\hline
\end{tabular}

DCIS, ductal carcinoma in situ; EST, expressed sequence tag; NKI ID, Netherlands Cancer Institute (Amsterdam, The Netherlands) identification number.

making this classification. We therefore included the cases classified as intermediately differentiated DCIS. Subsequently, we divided the sample set into one group of well/wellintermediately differentiated samples $(n=16)$ and a second group containing poorly/intermediately-poorly differentiated samples $(n=20)$. Supervised classification of these data revealed a set of 78 genes separating these two groups with an average performance of $89 \%$ (Table 5). 
(a) All in situ vs all invasive samples
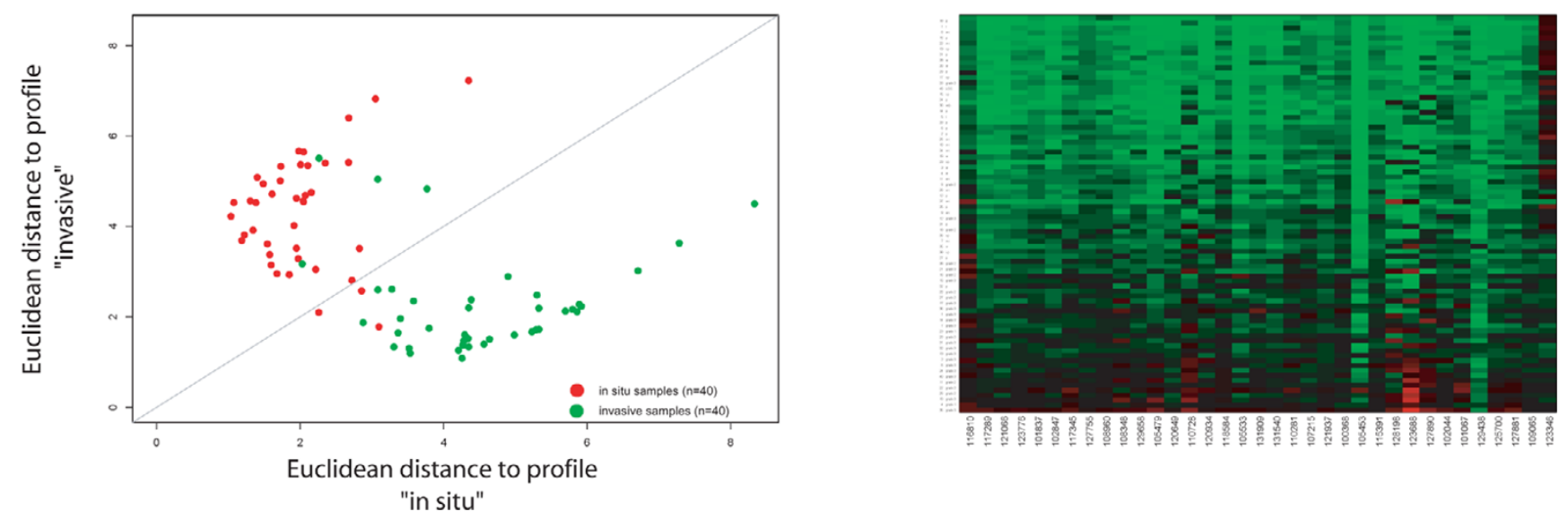

(b) Poorly differentiated DCIS vs invasive grade 3
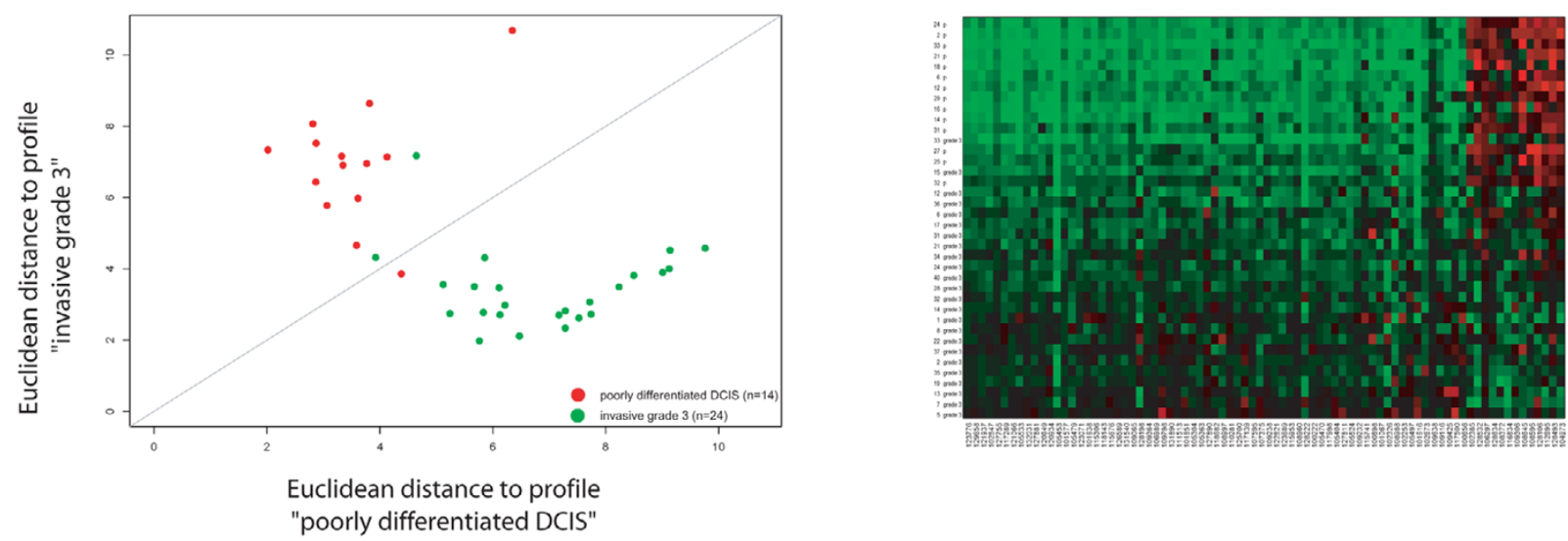

Euclidean distance and heatmaps of the in situ and invasive samples using the classifiers obtained after cross-validation. (a) All ductal carcinoma in situ (DCIS) $(n=40)$ and all invasive $(n=40)$ samples. The classifiers consist of 80 genes. (b) Poorly differentiated DCIS $(n=14)$ versus invasive grade 3 samples $(n=24)$ using a classifier of 35 genes. p, poorly differentiated.

We observed a separation of this data set in three distinct groups (Figure 3). One group contains one intermediatelypoorly differentiated sample (17\%) and 12 out of 14 poorly differentiated samples, and a second group all six well-differentiated samples and seven out of 10 well-intermediately differentiated samples. The third group shows no correlation with both profiles and consists of five out of six intermediatelypoorly and three out of 10 well-intermediately differentiated samples. This implies that this third group typifies mainly the intermediately-poorly differentiated samples. Well-intermediately differentiated samples are apparently very similar to welldifferentiated DCIS in their gene expression. These results are in accordance with the results of unsupervised hierarchical clustering of all in situ samples (Figure 4a).

Twenty-one genes are overlapping between the 43 genes of analysis set 3 and the 78 genes of analysis set 4 . It is known that many poorly differentiated in situ breast carcinomas do not express the ER. In our data set, nine of all 14 poorly differentiated DCIS samples (64\%) are negative for ER expression by IHC. There was a slight chance that our classifier would detect mainly the differences of ER-associated genes. We identified only one gene $(L I V-1)$, beside the ER itself, directly ER-regulated in the classifier of 43 genes. Additionally, we compared the 43 genes with 2,460 ER-associated genes identified by van 't Veer and colleagues [16]. Thirteen genes, including the ER itself, have been found in both gene lists. So, most of the genes in this 43-gene classifier have not been correlated to ER expression so far, indicating that the differences between well- and poorly differentiated DCIS samples are not originating from the ER status of the samples.

Remarkably, completely different gene lists are found describing the differences in gene expression between different in 
Breast Cancer Research Vol 8 No 5 Hannemann et al.

Table 3

List of 80 genes able to discriminate between poorly differentiated DCIS and invasive grade 3 breast tumours

\begin{tabular}{|c|c|c|c|c|}
\hline Rank & NKI ID & Symbol & Annotation & Accession no. \\
\hline 1 & 123776 & PIAS4 & Protein inhibitor of activated STAT protein & Н30547 \\
\hline 2 & 129658 & MGC13045 & DnaJ (Hsp40) homolog, subfamily $\mathrm{C}$, member 4 & AA996059 \\
\hline 3 & 121937 & FLJ10374 & Hypothetical protein FLJ10374 & AA676962 \\
\hline 4 & 102847 & YIF1 & $\begin{array}{l}\text { Putative transmembrane protein; homolog of yeast Golgi membrane protein Yif1p (Yip1p-interacting } \\
\text { factor) }\end{array}$ & $\mathrm{H} 79351$ \\
\hline 5 & 127755 & TGFB2 & Transforming growth factor, beta 2 & W47556 \\
\hline 6 & 117289 & MMP11 & Matrix metalloproteinase 11 (stromelysin 3) & AA045500 \\
\hline 7 & 104973 & SYNPO2 & Synaptopodin 2 & R31679 \\
\hline 8 & 121066 & $D A P K 3$ & Death-associated protein kinase 3 & AA973730 \\
\hline 9 & 128493 & GMFG & Glia maturation factor, gamma & Al311932 \\
\hline 10 & 105533 & $A R F 1$ & ADP-ribosylation factor 1 & W45572 \\
\hline 11 & 132031 & & NY-REN-24 antigen & AA918005 \\
\hline 12 & 127881 & NFIC & Nuclear factor I/C (CCAAT-binding transcription factor) & T59427 \\
\hline 13 & 120649 & KCTD5 & Potassium channel tetramerisation domain containing 5 & AA521027 \\
\hline 14 & 120934 & EIF4G1 & Eukaryotic translation initiation factor 4 gamma, 1 & $\mathrm{R} 37276$ \\
\hline 15 & 105453 & $P S A P$ & Prosaposin (variant Gaucher disease and variant metachromatic leukodystrophy) & N72215 \\
\hline 16 & 112695 & SYNPO2 & H. sapiens cDNA FLJ20767 fis, clone COL06986 & AA043349 \\
\hline 17 & 101577 & $B M / 1$ & Murine leukaemia viral (bmi-1) oncogene homolog & AA478036 \\
\hline 18 & 105479 & BAT3 & HLA-B-associated transcript-3 & AA434416 \\
\hline 19 & 123071 & C9orf82 & Hypothetical protein FLJ13657 & AA135972 \\
\hline 20 & 101638 & ID4 & Inhibitor of DNA binding 4, dominant negative helix-loop-helix protein & AA464856 \\
\hline 21 & 115306 & $L R P 16$ & LRP16 protein & AA456318 \\
\hline 22 & 118143 & $S T X 1 B 2$ & ESTs, moderately similar to ST1B_HUMAN SYNTAXIN 1B [H. sapiens] & $\mathrm{H} 41572$ \\
\hline 23 & 128106 & DUSP6 & Dual specificity phosphatase 6 & AA455254 \\
\hline 24 & 115676 & $R P S 15 A$ & Ribosomal protein S15a & AA411682 \\
\hline 25 & 108595 & CCL19 & Small inducible cytokine subfamily A (Cys-Cys), member 19 & AA680186 \\
\hline 26 & 126589 & C6orf166 & Hypothetical protein FLJ10342 & AA984953 \\
\hline 27 & 131540 & PRPF31 & DKFZP566J153 protein & $\mathrm{Al} 253017$ \\
\hline 28 & 109065 & SYT5 & & Н39018 \\
\hline 29 & 128198 & MMP11 & Matrix metalloproteinase 11 (stromelysin 3) & AA954935 \\
\hline 30 & 109364 & MYST2 & Histone acetyltransferase & H11938 \\
\hline 31 & 106989 & TNFSF13 & Tumour necrosis factor (ligand) superfamily, member 13 & AA443577 \\
\hline 32 & 109798 & & & T82459 \\
\hline 33 & 131890 & $\mathrm{CDH} 1$ & Cadherin 1, type 1, E-cadherin (epithelial) & Al671174 \\
\hline 34 & 111513 & COG3 & H. sapiens clone 25226 mRNA sequence & AA461166 \\
\hline 35 & 108645 & HMGCS2 & 3-Hydroxy-3-methylglutaryl-Coenzyme A synthase 2 (mitochondrial) & AA496149 \\
\hline 36 & 101651 & TRAP1 & Heat shock protein 75 & AA497020 \\
\hline 37 & 105304 & $L R P 16$ & LRP16 protein & W52182 | AA284285 \\
\hline 38 & 105363 & $A R L 7$ & ADP-ribosylation factor-like 7 & AA485683 \\
\hline 39 & 127890 & PTMS & Parathymosin & AA458981 \\
\hline 40 & 118682 & NBS1 & Nijmegen breakage syndrome 1 (nibrin) & H98655 \\
\hline
\end{tabular}


Table 3 (Continued)

\begin{tabular}{|c|c|c|c|c|}
\hline 41 & 108997 & PTTG1IP & Pituitary tumour-transforming 1 interacting protein & AA156461 \\
\hline 42 & 110281 & HSPA1L & Heat shock 70-kD protein-like 1 & $\mathrm{H} 17513$ \\
\hline 43 & 125700 & APC2 & Adenomatous polyposis coli like & AA976241 \\
\hline 44 & 117139 & $A L D O B$ & Aldolase B, fructose-bisphosphate & $\mathrm{H} 72098$ \\
\hline 45 & 107595 & Sox17 & SRY-box 17 & AA427400| Al732705 \\
\hline 46 & 107375 & NUCKS & Similar to rat nuclear ubiquitous casein kinase 2 & AA137266 \\
\hline 47 & 109238 & $B S G$ & Basigin (OK blood group) & AA436440 \\
\hline 48 & 122821 & NSE2 & ESTs & Н30453 \\
\hline 49 & 123689 & LOC339123 & STIP1 homology and U-Box containing protein 1 & R54844 \\
\hline 50 & 115953 & LOC146542 & Human Chromosome 16 BAC clone CIT987SK-A-635H12 & AA455010 \\
\hline 51 & 108960 & $G A B R D$ & & $\mathrm{H} 41122$ \\
\hline 52 & 128222 & GLUL & Glutamate-ammonia ligase (glutamine synthase) & Al000103 \\
\hline 53 & 100222 & NFIX & Nuclear factor I/X (CCAAT-binding transcription factor) & AA406269 \\
\hline 54 & 105470 & ISYNA1 & Myo-inositol 1-phosphate synthase A1 & AA454554 \\
\hline 55 & 117998 & $R B M 9$ & RNA binding motif protein 9 & Н03903 \\
\hline 56 & 105404 & GDF15 & Prostate differentiation factor & N26311 \\
\hline 57 & 127811 & TOB1 & Transducer of ERBB2, 1 & W96163 \\
\hline 58 & 105524 & RPS6KA4 & Ribosomal protein S6 kinase, 90-kD, polypeptide 4 & AA443601 \\
\hline 59 & 109232 & $B C K D H A$ & Branched chain keto acid dehydrogenase E1, alpha polypeptide (maple syrup urine disease) & AA477298 \\
\hline 60 & 115741 & $A P P L$ & Adaptor protein containing $\mathrm{pH}$ domain, PTB domain and leucine zipper motif & AA436158 \\
\hline 61 & 100898 & ELF3 & E74-like factor 3 (ets domain transcription factor, epithelial-specific) & AA434373 \\
\hline 62 & 101067 & MAP7 & Microtubule-associated protein 7 & R77252 | R77251 \\
\hline 63 & 109306 & $A Q P 1$ & Aquaporin 1 (channel-forming integral protein, $28 \mathrm{kD}$ ) & $\mathrm{H} 24316$ \\
\hline 64 & 102326 & CYC1 & Cytochrome c-1 & AA447774 \\
\hline 65 & 108988 & MALAT1 & Histone deacetylase 3 & $\mathrm{H} 88540$ \\
\hline 66 & 102253 & ACTG2 & Actin, gamma 2, smooth muscle, enteric & T60048 \\
\hline 67 & 116834 & GPC1 & Glypican 1 & AA455896 \\
\hline 68 & 105497 & HNRPK & Heterogeneous nuclear ribonucleoprotein $\mathrm{K}$ & W85697 \\
\hline 69 & 108372 & $L C P 1$ & Lymphocyte cytosolic protein 1 (L-plastin) & W73144 \\
\hline 70 & 128634 & PRCP & Prolylcarboxypeptidase (angiotensinase C) & Al360366 \\
\hline 71 & 106297 & PHF17 & Hypothetical protein FLJ22479 & AA136664 \\
\hline 72 & 101616 & KRT19 & Keratin 19 & AA464250 \\
\hline 73 & 128532 & $\angle T B$ & Lymphotoxin beta (TNF superfamily, member 3) & Al351740 \\
\hline 74 & 102385 & $F 13 A 1$ & Coagulation factor $\mathrm{XIII}, \mathrm{A} 1$ polypeptide & AA449742 \\
\hline 75 & 102673 & WHSC1L1 & Wolf-Hirschhorn syndrome candidate 1 -like 1 & T97900 \\
\hline 76 & 109638 & $C X X C 1$ & CpG binding protein & T60082 \\
\hline 77 & 109116 & $F B L$ & Fibrillarin & AA663986 \\
\hline 78 & 109425 & TUBB & Tubulin, beta polypeptide & AA427899 \\
\hline 79 & 117500 & & EST & AA621138 \\
\hline 80 & 100656 & UBE2C & Ubiquitin carrier protein E2-C & AA430504 \\
\hline
\end{tabular}

DCIS, ductal carcinoma in situ; EST, expressed sequence tag; NKI ID, Netherlands Cancer Institute (Amsterdam, The Netherlands) identification number. 
Figure 3

(a) Well vs poorly differentiated DCIS
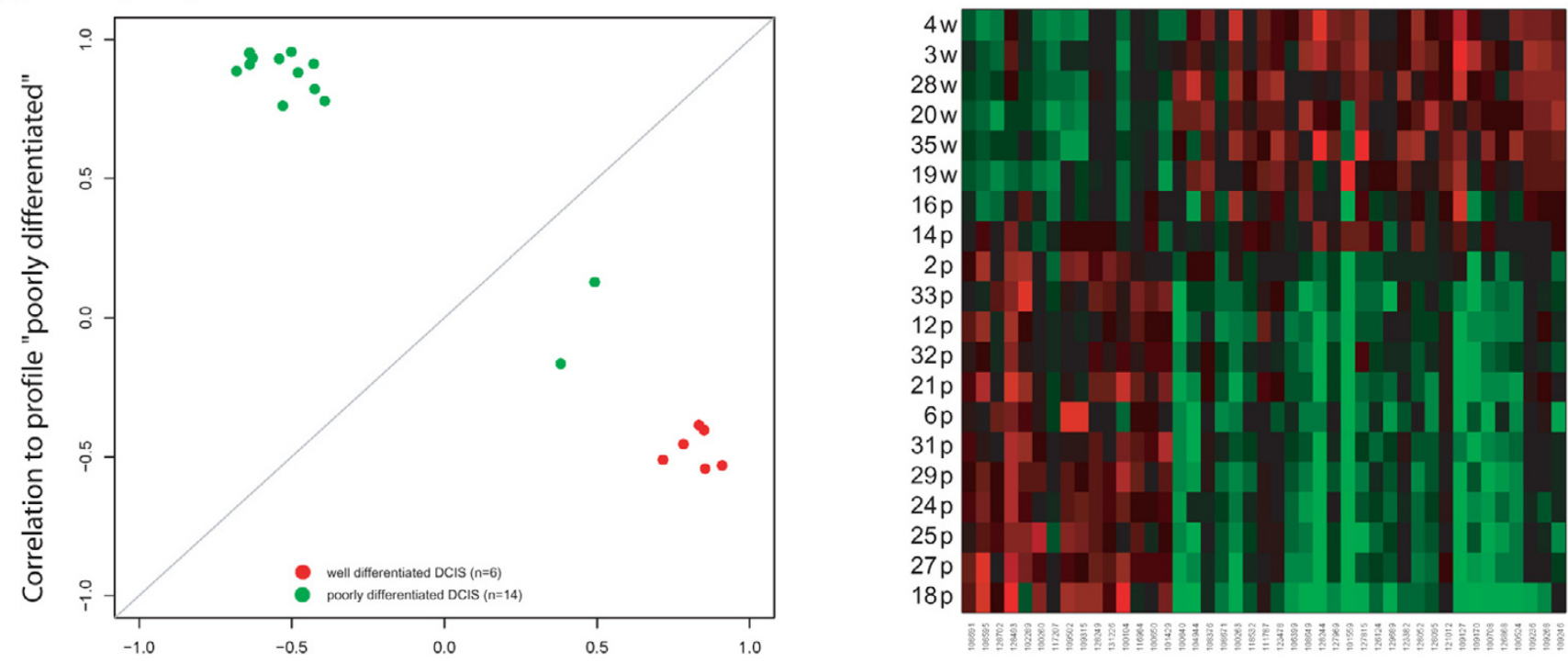

Correlation to profile "well differentiated"

(b) Well/well-intermediately vs intermediately-poorly/poorly differentiated DCIS
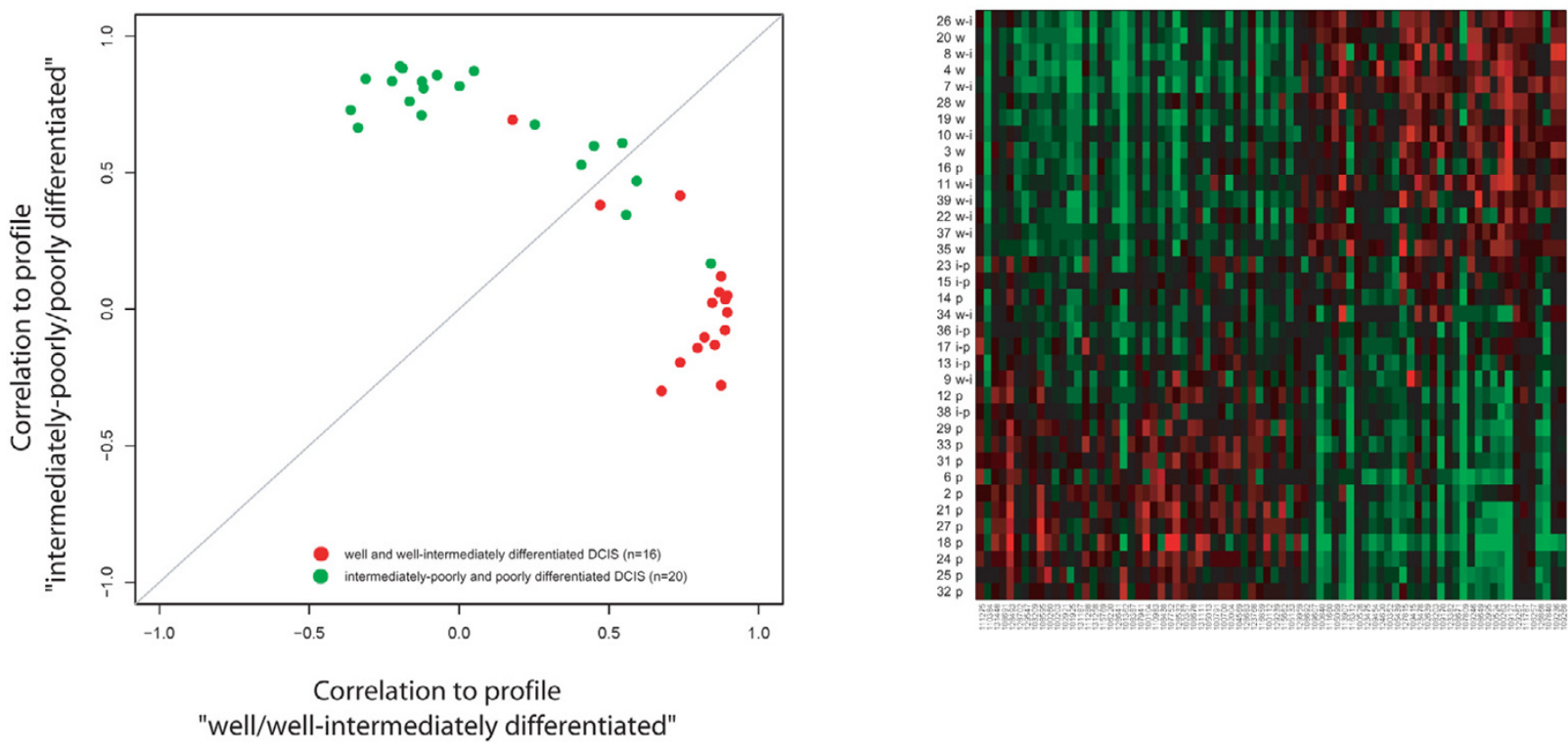

Correlation plots and heatmaps of the in situ samples using the classifiers obtained after cross-validation. (a) Well- $(n=6)$ versus poorly $(n=14)$ differentiated ductal carcinoma in situ (DCIS). The classifiers consist of 43 genes. (b) Well-/well-intermediately $(n=16)$ versus intermediatelypoorly/poorly $(n=20)$ differentiated DCIS using a classifier of 78 genes. i-p, intermediately-poorly differentiated; $p$, poorly differentiated; w, well differentiated; $w$-i, well-intermediately differentiated.

situ samples, on one hand, and DCIS and invasive samples on the other hand. These findings may indicate that gene regulation involved in progression from in situ to invasive breast cancer affects molecular mechanisms other than the mechanisms responsible for the development of the different types of DCIS.

\section{Discussion}

Although studies to identify gene expression signatures in DCIS are limited by difficulties in obtaining frozen material from DCIS, we were able to collect a relatively large series of DCIS cases for this purpose. It should be kept in mind that we did 
Table 4

List of 43 genes able to discriminate between well- and poorly differentiated DCIS

\begin{tabular}{|c|c|c|c|c|}
\hline Rank & NKI ID & Symbol & Annotation & Accession no. \\
\hline 1 & 108691 & ACK1 & Activated p21cdc42Hs kinase & AA427891 \\
\hline 2 & 109246 & $B C L 2$ & B-cell CLL/lymphoma 2 & W63749 \\
\hline 3 & 109268 & $A L D H 3 A 2$ & Aldehyde dehydrogenase 3 family, member A2 & AA633569 \\
\hline 4 & 109236 & $B T D$ & Biotinidase & R17765 \\
\hline 5 & 108595 & CCL19 & Small inducible cytokine subfamily A (Cys-Cys), member 19 & AA680186 \\
\hline 6 & 100524 & CELSR2 & Cadherin, EGF LAG seven-pass G-type receptor 2, flamingo (Drosophila) homolog & H39187 \\
\hline 7 & 126868 & TMC4 & DKFZP586J0619 protein & AA991211 \\
\hline 8 & 100708 & SLC39A6 & LIV-1 protein, oestrogen regulated & $\mathrm{H} 29315$ \\
\hline 9 & 109170 & $\mathrm{C} 4 \mathrm{~A}$ & Complement component $4 \mathrm{~A}$ & AA664406 \\
\hline 10 & 109127 & ESR1 & Oestrogen receptor 1 & AA291749 \\
\hline 11 & 128702 & & EST & Al313031 \\
\hline 12 & 121012 & HSHIN1 & Hin-1 & AA902831 \\
\hline 13 & 128095 & PCSK6 & Paired basic amino acid cleaving system 4 & W85807 \\
\hline 14 & 128052 & ARHGEF7 & PAK-interacting exchange factor beta & AA452871 \\
\hline 15 & 128493 & GMFG & Glia maturation factor, gamma & Al311932 \\
\hline 16 & 123382 & HIG1 & Likely ortholog of mouse hypoxia induced gene 1 & T74105 \\
\hline 17 & 129689 & C1orf21 & Chromosome 1 open reading frame 21 & AA406569 \\
\hline 18 & 102289 & ETFA & Electron-transfer-flavoprotein, alpha polypeptide (glutaric aciduria II) & T57919 \\
\hline 19 & 126124 & FLJ20152 & Hypothetical protein & AA918685 \\
\hline 20 & 127815 & PLAT & Plasminogen activator, tissue & R38933 \\
\hline 21 & 101559 & NPY1R & Neuropeptide $Y$ receptor $Y 1$ & R43817 \\
\hline 22 & 100260 & MAL & Mal, T-cell differentiation protein & AA227885 \\
\hline
\end{tabular}


Breast Cancer Research Vol 8 No 5 Hannemann et al.

Table 4 (Continued)

List of $\mathbf{4 3}$ genes able to discriminate between well- and poorly differentiated DCIS

\begin{tabular}{|c|c|c|c|c|}
\hline 23 & 127969 & CRYAA & Crystallin, alpha A & H84722 \\
\hline 24 & 128244 & SERPINA3 & Serine (or cysteine) proteinase inhibitor, clade A (alpha-1 antiproteinase, antitrypsin), member 3 & AA704242 \\
\hline 25 & 108649 & & Human clone 23948 mRNA sequence & $\mathrm{H} 15114$ \\
\hline 26 & 106399 & GRTP1 & Hypothetical protein FLJ22474 & N52651 \\
\hline 27 & 123478 & FLJ14712 & Hypothetical protein FLJ14712 & N79050 \\
\hline 28 & 117207 & EMP3 & Epithelial membrane protein 3 & W73810 \\
\hline 29 & 111787 & ZNF451 & H. sapiens cDNA FLJ13010 fis, clone NT2RP3000542 & AA486412 \\
\hline 30 & 109502 & KITLG & H. sapiens cDNA: FLJ21592 fis, clone COL07036 & $\mathrm{H} 11088$ \\
\hline 31 & 109315 & UCP2 & Uncoupling protein 2 (mitochondrial, proton carrier) & $\mathrm{H} 61243$ \\
\hline 32 & 118532 & NUPL1 & PRO2463 protein & AA772502 \\
\hline 33 & 100263 & $M Y B$ & V-myb avian myeloblastosis viral oncogene homolog & N49284 \\
\hline 34 & 128249 & $C D 3 E$ & CD3E antigen, epsilon polypeptide (TiT3 complex) & AA933862 \\
\hline 35 & 131226 & $I L 7 R$ & Interleukin 7 receptor & T65739 \\
\hline 36 & 100104 & SELL & Selectin L (lymphocyte adhesion molecule 1) & H00662 \\
\hline 37 & 108671 & BCAT2 & Branched chain aminotransferase 2, mitochondrial & AA436410 \\
\hline 38 & 116984 & ATP5B & ATP synthase, $\mathrm{H}+$ transporting, mitochondrial F1 complex, beta polypeptide & AA708298 \\
\hline 39 & 108376 & LAMA3 & Laminin, alpha 3 (nicein [150 kD], kalinin [165 kD], BM600 [150 kD], epilegrin) & AA001432 \\
\hline 40 & 104944 & SLC7A2 & Solute carrier family 7 (cationic amino acid transporter, $y+$ system), member 2 & R26163 \\
\hline 41 & 100840 & THOC1 & Nuclear matrix protein $\mathrm{p} 84$ & AA129297 \\
\hline 42 & 100650 & SHFM1 & Deleted in split-hand/split-foot 1 region & H85464 \\
\hline 43 & 101429 & SIAT1 & Sialyltransferase 1 (beta-galactoside alpha-2,6-sialytransferase) & AA598652 \\
\hline
\end{tabular}

DCIS, ductal carcinoma in situ; EST, expressed sequence tag; NKI ID, Netherlands Cancer Institute (Amsterdam, The Netherlands) identification number. 
Table 5

\begin{tabular}{|c|c|c|c|c|}
\hline Rank & NKI ID & Symbol & Annotation & Accession no. \\
\hline 1 & 111275 & & EST & $\mathrm{H} 20757$ \\
\hline 2 & 109268 & $A L D H 3 A 2$ & Aldehyde dehydrogenase 3 family, member A2 & AA633569 \\
\hline 3 & 109236 & $B T D$ & Biotinidase & R17765 \\
\hline 4 & 110384 & KPNA2 & Karyopherin alpha 2 (RAG cohort 1, importin alpha 1) & AA676460 \\
\hline 5 & 131448 & PLEKHG1 & KIAA1209 protein & Al301815 \\
\hline 6 & 108691 & $A C K 1$ & Activated p21cdc $42 \mathrm{Hs}$ kinase & AA427891 \\
\hline 7 & 107840 & EPC1 & ESTs & AA120875 \\
\hline 8 & 126868 & TMC4 & DKFZP586J0619 protein & AA991211 \\
\hline 9 & 106257 & FLJ32499 & H. sapiens cDNA FLJ12749 fis, clone NT2RP2001149 & W56590 \\
\hline 10 & 128493 & GMFG & Glia maturation factor, gamma & Al311932 \\
\hline 11 & 128702 & & & Al313031 \\
\hline 12 & 129547 & METAP2 & Methionine aminopeptidase; elF-2-associated p67 & AA283030 \\
\hline 13 & 111787 & ZNF451 & H. sapiens cDNA FLJ13010 fis, clone NT2RP3000542 & AA486412 \\
\hline 14 & 103209 & $R B M S 1$ & H. sapiens mRNA; cDNA DKFZp564H0764 (from clone DKFZp564H0764) & R62566 \\
\hline 15 & 108595 & CCL19 & Small inducible cytokine subfamily A (Cys-Cys), member 19 & AA680186 \\
\hline 16 & 129267 & & & AA609203 \\
\hline 17 & 109127 & ESR1 & Oestrogen receptor 1 & AA291749 \\
\hline 18 & 100263 & MYB & V-myb avian myeloblastosis viral oncogene homolog & N49284 \\
\hline 19 & 100524 & CELSR2 & Cadherin, EGF LAG seven-pass G-type receptor 2, flamingo (Drosophila) homolog & Н39187 \\
\hline 20 & 100260 & $M A L$ & Mal, T-cell differentiation protein & AA227885 \\
\hline 21 & 102995 & PIGT & CGI-06 protein & H82992 \\
\hline 22 & 108649 & & Human clone 23948 mRNA sequence & $\mathrm{H} 15114$ \\
\hline 23 & 109246 & $B C L 2$ & B-cell CLL/lymphoma 2 & W63749 \\
\hline 24 & 100203 & TNFAIP3 & Tumour necrosis factor, alpha-induced protein 3 & AA476272 \\
\hline 25 & 107809 & $X B P 1$ & X-box binding protein 1 & W90128 \\
\hline 26 & 102921 & & H. sapiens mRNA; cDNA DKFZp434D0818 (from clone DKFZp434D0818) & N95578 \\
\hline
\end{tabular}


Breast Cancer Research Vol 8 No 5 Hannemann et al.

Table 5 (Continued)

List of 78 genes able to discriminate between well/well-intermediately and intermediately-poorly/poorly differentiated DCIS

\begin{tabular}{|c|c|c|c|c|}
\hline 27 & 108671 & BCAT2 & Branched chain aminotransferase 2 , mitochondrial & AA436410 \\
\hline 28 & 101925 & $E Z H 2$ & & AA430744 \\
\hline 29 & 123382 & HIG1 & Likely ortholog of mouse hypoxia induced gene 1 & T74105 \\
\hline 30 & 131187 & KPNA2 & Karyopherin alpha 2 (RAG cohort 1 , importin alpha 1) & AA489087 \\
\hline 31 & 111288 & & H. sapiens mRNA; cDNA DKFZp564C2063 (from clone DKFZp564C2063) & AA416628 \\
\hline 32 & 109170 & $\mathrm{C} 4 \mathrm{~A}$ & Complement component $4 \mathrm{~A}$ & AA664406 \\
\hline 33 & 108203 & TEGT & Testis enhanced gene transcript (BAX inhibitor 1 ) & AA629591 \\
\hline 34 & 102639 & $E M L 2$ & Microtubule-associated protein like echinoderm EMAP & R27580 \\
\hline 35 & 131258 & PSMA7 & Proteasome (prosome, macropain) subunit, alpha type, 7 & Al318565 \\
\hline 36 & 123478 & FLJ14712 & Hypothetical protein FLJ14712 & N79050 \\
\hline 37 & 109415 & FCGBP & Fc fragment of $\lg G$ binding protein & R52030 \\
\hline 38 & 127815 & PLAT & Plasminogen activator, tissue & R38933 \\
\hline 39 & 115769 & & ESTs & AA406313 \\
\hline 40 & 106220 & GIMAP5 & Hypothetical protein FLJ11296 & AA150443 \\
\hline 41 & 128641 & PTTG1 & Pituitary tumour-transforming 1 & Al362866 \\
\hline 42 & 105439 & TGOLN2 & Trans-Golgi network protein (46-, 48-, 51-kD isoforms) & Т81338 \\
\hline 43 & 101362 & $E R B B 2$ & $\begin{array}{l}\text { V-erb-b2 avian erythroblastic leukaemia viral oncogene homolog } 2 \text { (neuro/glioblastoma } \\
\text { derived oncogene homolog) }\end{array}$ & AA446928 \\
\hline 44 & 108387 & $I D H 2$ & Isocitrate dehydrogenase 2 (NADP+), mitochondrial & AA679907 \\
\hline 45 & 100352 & TGOLN2 & Trans-Golgi network protein (46-, 48-, 51-kD isoforms) & H82891 \\
\hline 46 & 107941 & PLAC8 & Hypothetical protein & AA150263 \\
\hline 47 & 100104 & SELL & Selectin L (lymphocyte adhesion molecule 1) & H00662 \\
\hline 48 & 110983 & DLEU1 & Deleted in lymphocytic leukaemia, 1 & AA425755 \\
\hline 49 & 108438 & GRB7 & Growth factor receptor-bound protein 7 & H53703 \\
\hline 50 & 107752 & $P A G$ & Phosphoprotein associated with GEMs & N50114 \\
\hline 51 & 128532 & $L T B$ & Lymphotoxin beta (TNF superfamily, member 3) & Al351740 \\
\hline 52 & 124620 & ASTN2 & KIAA0634 protein & AA404602 \\
\hline 53 & 102357 & $\mathrm{CHN1}$ & Chimerin (chimaerin) 1 & AA598668 \\
\hline
\end{tabular}


List of 78 genes able to discriminate between well/well-intermediately and intermediately-poorly/poorly differentiated DCIS

\begin{tabular}{|c|c|c|c|c|}
\hline 54 & 109454 & $A K R 7 A 2$ & Aldo-keto reductase family 7 , member A2 (aflatoxin aldehyde reductase) & T62865 \\
\hline 55 & 108678 & CASP10 & Caspase 10, apoptosis-related cysteine protease & H80712 \\
\hline 56 & 131111 & CUGBP2 & CUG triplet repeat, RNA-binding protein 2 & AA047257 \\
\hline 57 & 123475 & C9orf87 & Hypothetical protein FLJ10493 & N53432 \\
\hline 58 & 105013 & & EST & H61003 \\
\hline 59 & 100791 & $T D G$ & Thymine-DNA glycosylase & AA496947 \\
\hline 60 & 100528 & $B C L 2 L 2$ & BCL2-like 2 & AA454588 \\
\hline 61 & 116312 & FLJ14299 & Hypothetical protein FLJ14299 & AA453170 \\
\hline 62 & 100700 & TRIB2 & GS3955 protein & AA458653 \\
\hline 63 & 102004 & PIK3R1 & Phosphoinositide-3-kinase, regulatory subunit, polypeptide 1 (p85 alpha) & R54050 \\
\hline 64 & 104569 & MYO1B & $\begin{array}{l}\text { H. sapiens cDNA FLJ20153 fis, clone COL08656, highly similar to AJ001381 H. sapiens } \\
\text { incomplete cDNA for a mutated allele }\end{array}$ & N95358 \\
\hline 65 & 113907 & SNRPB2 & Small nuclear ribonucleoprotein polypeptide B" & H00286 \\
\hline 66 & 128683 & WASL & Wiskott-Aldrich syndrome-like & $\mathrm{Al} 261600$ \\
\hline 67 & 123768 & DUSP22 & Mitogen-activated protein kinase phosphatase $x$ & H42417 \\
\hline 68 & 105099 & RET & $\begin{array}{l}\text { Ret proto-oncogene (multiple endocrine neoplasia MEN2A, MEN2B and medullary thyroid } \\
\text { carcinoma 1, Hirschsprung disease) }\end{array}$ & H24956 \\
\hline 69 & 116859 & STMN1 & Leukaemia-associated phosphoprotein p18 (stathmin) & AA873060 \\
\hline 70 & 111660 & FLJ13710 & ESTs & AA120866 \\
\hline 71 & 100112 & SAA1 & Serum amyloid $\mathrm{A} 1$ & $\mathrm{H} 25546$ \\
\hline 72 & 100840 & THOC1 & Nuclear matrix protein p84 & AA129297 \\
\hline 73 & 129239 & & EST, Moderately similar to AF119917 63 PRO2831 [H. sapiens] & W95750 \\
\hline 74 & 115662 & GIMAP4 & Hypothetical protein FLJ11110 & AA406363 \\
\hline 75 & 109607 & HTPAP & ESTs & T48412 \\
\hline 76 & 108692 & EMP2 & Epithelial membrane protein 2 & T88721 \\
\hline 77 & 105133 & JUNB & Jun B proto-oncogene & N94468 \\
\hline 78 & 129959 & $\begin{array}{l}\text { LOC28335 } \\
2\end{array}$ & EST & $\mathrm{Al023540}$ \\
\hline
\end{tabular}

DCIS, ductal carcinoma in situ; EST, expressed sequence tag; NKI ID, Netherlands Cancer Institute (Amsterdam, The Netherlands) identification number. 


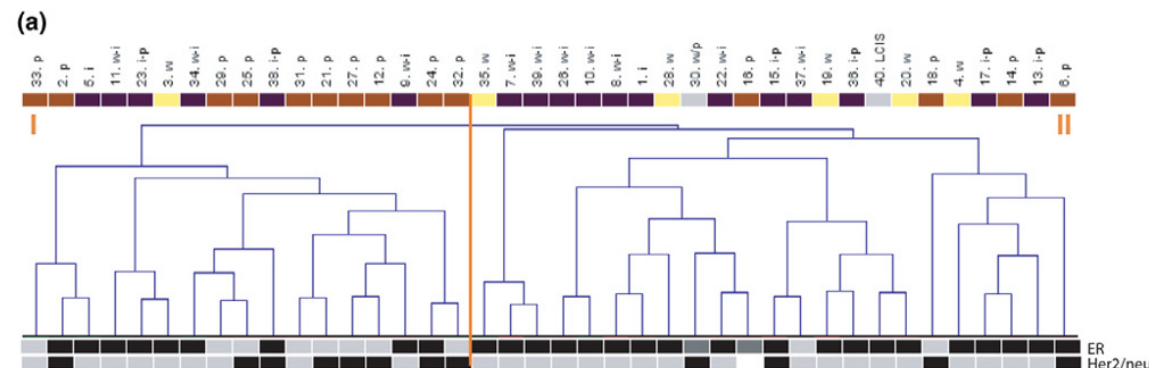

(b)

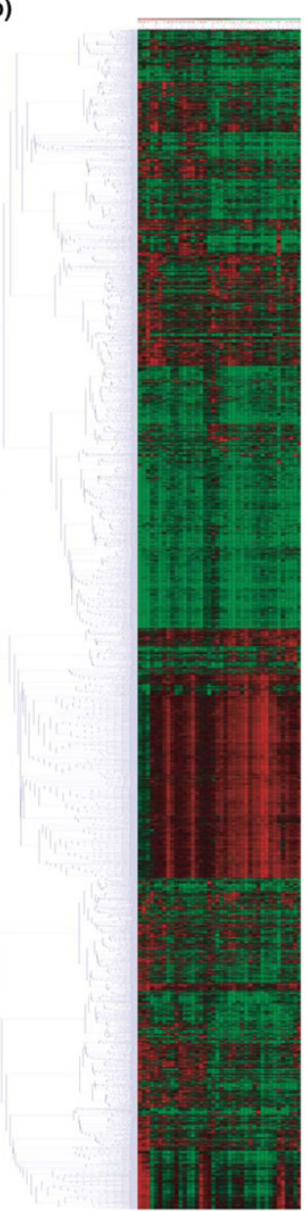

(c)

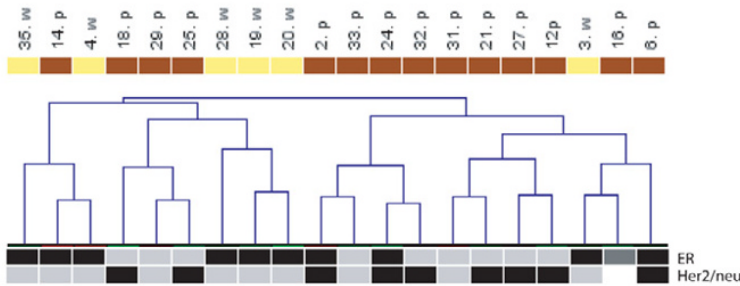

(d)

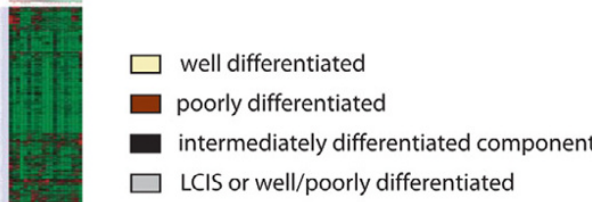

ER and Her2/neu status

$\square \operatorname{pos}(\mathrm{IHC})$
$\square$ neg $(\mathrm{IHC})$
$\square$ pos $(\log 2$ ratio $>-0.5)$
$\square \quad$ neg $(\log 2$ ratio $<-0.5)$

Unsupervised hierarchical clustering of the in situ samples. (a) Dendrogram of all 40 in situ samples. (b) Scaled-down representation of the entire cluster of (a) (5,788 genes). (c) Dendrogram of only the well- $(n=6)$ and poorly $(n=14)$ differentiated ductal carcinoma in situ (DCIS) cases. (d) Entire cluster of (c) (4,493 genes). Yellow indicates well-differentiated DCIS, brown indicates poorly differentiated DCIS, black indicates DCIS samples with an intermediately differentiated component, and gray indicates special cases. i, intermediately differentiated; IHC, immunohistochemistry; i$p$, intermediately-poorly differentiated; LCIS, lobular carcinoma in situ; $p$, poorly differentiated; $w$, well differentiated; $w$-i, well-intermediately differentiated.

not have a sufficient number of cases to validate the gene expression signatures that we identified.

We were able to show that well- $(n=6)$ and poorly $(n=14)$ differentiated DCIS show different gene expression profiles and can be distinguished by a classifier of 43 genes. Most of the genes differentially expressed between well- and poorly differentiated DCIS are involved in metabolism (for example, $B T D, E T F A, G M F G$, and PLAT) and cell communication (for example, ESR1, ACK1, CELSR2, and CCL19).

One of the top genes in the 43-gene classifier is BCL2. The mRNA expression of this anti-apoptotic protein is upregulated in the well-differentiated samples. In addition to its anti-apop- 
totic function, BCL2 has a suggested role in neuro-endocrine differentiation in colon carcinomas [31] and its downregulation is associated with poor prognosis in breast cancer [32].

Twenty-eight of the 43 genes are upregulated and 15 genes are downregulated in the well-differentiated samples (Figure 3a). Whereas a number of the 28 upregulated genes are involved in DNA binding, no genes fulfilling this function are on the list of the 15 downregulated genes. Conversely, genes involved in phosphate metabolism (for example, GMFG, $A C K 1$, and $A T P 5 B$ ) can be found within the 15 downregulated, but not in the 28 upregulated, genes.

It is known that HER2 is overexpressed in poorly differentiated DCIS in approximately $42 \%$ of the cases [7], and it has been suggested that HER2 overexpression is an early step in the evolution of a distinct type of breast carcinoma. In our data set of all in situ samples, we found a positive log2-ratio for HER mRNA expression in six of 14 poorly differentiated DCIS cases $(43 \%)$ and in one case of intermediately-poorly differentiated DCIS. In all the other in situ samples, the log2-ratios of HER2 are negative. These results are in agreement with the hypothesis that HER2 overexpression is an early event in the development of poorly differentiated in situ breast carcinomas.

Supervised classification of well-, well-intermediately, intermediately-poorly, and poorly differentiated DCIS samples (analysis set 4) showed a separation of these samples in three groups: a 'good' group, a 'poor' group, and an 'intermediate' group containing mostly samples that were identified as intermediately-poorly differentiated samples by pathologists. This group also contains some samples pathologically classified as well-intermediately differentiated, whereas most of these samples fall in the 'good' group. These results indicate that welland well-intermediately differentiated DCIS are more similar to each other than poorly and intermediately-poorly differentiated DCIS are. Following this idea, well- and well-intermediately differentiated samples may be considered to be one group, whereas poorly and intermediately-poorly differentiated samples seem to be two distinct groups of DCIS. If these results can be validated in additional studies, this classification could help to decrease controversial classification of DCIS due to interobserver variability and to recognise well-differentiated DCIS with more accuracy.

Within the gene lists describing the differences between welland poorly differentiated DCIS, a number of genes refer to proteins for which antibodies are available. There is no single gene discriminating between the different types of DCIS, but it has to be investigated whether a combination of protein stainings in a patient's tissue can assist in better classification of DCIS. From the study presented here, potential candidates for such an approach are Bcl-2, Ack1, CCL19, and CELSR2, among others.
Thirty-five genes are able to describe the global differences in gene expression between in situ and invasive breast tumour samples. This classifier contains many genes involved in signal transduction (for example, APC2, DAPK3, ADM, ARF1, and IQGAP1) and cell growth and maintenance (TGFB2, PTMS, $P S A P, T U B B 2$, and MAP7).

The most likely model describing the progression from in situ to invasive breast cancer lesions is the existence of distinct pathways for the evolution of well- and poorly differentiated DCIS. Following this idea, well-differentiated in situ lesions develop into grade 1 IDC, whereas poorly differentiated samples develop into grade 3 IDC $[5,6]$. We therefore performed supervised classification on the set of poorly differentiated DCIS $(n=14)$ and grade 3 invasive breast cancer $(n=24)$.

Approximately 80 genes discriminate poorly differentiated in situ from grade 3 invasive breast carcinomas. Thirteen of these 80 genes are upregulated and 67 genes are downregulated in poorly differentiated DCIS samples. The genes in this classifier are involved mostly in cell growth and protein metabolism. Many of them have a function in protein binding (for example, $L C P 1, T R A P 1, I D 4, T O B 1$, and $C D H)$ and nucleic acid binding (for example, FBL, PIAS4, ELF3, EIF4G1, NBS1, and WHSC1L1).

A limited number of previous studies have addressed gene expression profiles in DCIS, and most of these studies have analysed a small number of samples. One study by Seth and colleagues [20] compared one case of low- to intermediategrade DCIS with one case of high-grade DCIS with an invasive component and identified genes upregulated or downregulated in the low- to intermediate-grade DCIS case. Adeyinka and colleagues [19] studied six cases of DCIS with necrosis and four samples of DCIS without necrosis and identified a signature of 69 transcripts differentially expressed between these two groups. Ma and colleagues [33] used laser capture microdissection from paraffin-embedded material followed by gene expression profiling to identify molecular signatures in premalignant, preinvasive, and invasive stages of breast cancer. The results of their study suggested that tumour grade, rather than tumour stage, is associated with distinct gene expression patterns and that changes in gene expression required for invasive growth are already present in the DCIS stage [33]. In the study presented here, we compared the gene expression profiles of poorly differentiated DCIS lesions with those in grade 3 invasive breast tumours. In contrast to $\mathrm{Ma}$ and colleagues, we did not compare paired samples from the same patient but compared two groups of tumours. The 80 -gene signature we identified is different from the signatures describing the differences between different grades of DCIS lesions. Schuetz and colleagues [34] identified gene expression signatures of in situ and invasive breast cancer by using 18 paired samples and combining laser capture microdissection and gene expression profiling on oligonucleotide 
microarrays. They showed that 546 probes were differentially expressed between DCIS and IDC. From the 18 genes they validated by real-time polymerase chain reaction, four (MMP11, PLAU, BGN, and FAP) are also present in our filtered data sets of significantly regulated probe sets comparing DCIS and invasive samples. They all show the same expression pattern as described by Schuetz and colleagues and are expressed at higher levels in the groups of invasive tumours. One of these genes (MMP11) is also part of the 35-gene and 80-gene classifiers. MMP11 and PLAU have already been correlated to invasion and poor prognosis [35,36]. FAP (seprase) is a membrane-bound protease that has been suggested to reduce the dependence of breast cancer cells on exogenous growth factors in vitro and thereby to facilitate tumour growth and metastasis [37]. Allinen and colleagues [38] identified comprehensive gene expression profiles of the different cell types in normal breast, DCIS, and invasive breast cancer tissue. These data show that dramatic gene expression changes occur between normal breast tissue and breast carcinomas and that these changes are already present at the $\mathrm{DCIS}$ stage. These results also suggest a role of the chemokines CXCL12 and CXCL14 in breast tumourigenesis. Neither chemokine is present on our array platform, but CXCR4, which is the receptor for CXCL12, is. CXCR4 does not appear in the set of significantly regulated genes, indicating that it does not play a crucial role in our series of tumours, which reflects the data of a mixed population of cells enriched for tumour cells, whereas Allinen and colleagues performed gene expression profiling on microdissected cell populations.

A recent study by Nagaraja and colleagues [39] describes gene expression patterns corresponding to normal breast, noninvasive breast cancer, and invasive breast cancer by using several cell lines. They identified genes involved in cellcell and cell-matrix interactions which were altered in their expression. A set of nine genes was sufficient to distinguish between invasive and non-invasive cell lines [39]. From this set of nine transcripts, six could be matched to our array platform. For three of them (cadherin 11, annexin A1, and vimentin), we observe the same expression pattern as published by Nagaraja and colleagues for the transition from in situ to invasive carcinoma. The other three transcripts (S100A8, claudin 3, and cadherin 1) are upregulated in the invasive cancer cell line in the data set of Nagaraja and colleagues, whereas we see a downregulation in the invasive grade 3 tumours compared with the group of poorly differentiated samples. This may be due to the fact that Nagaraja and colleagues generated in vitro data, which we compared with our human breast cancer data set.

Porter and colleagues [40] identified a subset of genes that are significantly regulated in DCIS or invasive carcinomas. They identified 26 genes that were differentially expressed between normal and DCIS samples or intermediate- and highgrade DCIS, respectively. From these, only XBP1 is present in one of our classifiers (78 genes). Porter and colleagues describe this transcript as tumour-specific, meaning upregulated in in situ and invasive tumours compared with their normal samples. We find that XBP1 is significantly more highly expressed in well- and well-intermediately differentiated DCIS samples than in poorly/intermediately-poorly differentiated ones.

Wulfkuhle and colleagues [41] performed proteomic analyses of six matched normal and DCIS samples of the human breast. They identified proteins that are more highly expressed in individual DCIS samples and that are involved in cytoskeletal regulation or vesicular trafficking or have chaperone activity. From the 15 proteins from which the expression has been validated by $\mathrm{IHC}, 12$ are present as probes on our array platform. Three of those (profilin, stathmin, and prohibitin) are differentially regulated between DCIS and invasive samples, and all three show a higher expression in the invasive samples than in the DCIS samples. This is in line with the paper of Wulfkuhle and colleagues, which describes a higher expression of these proteins in the DCIS samples than in normal tissue. This indicates that changes in gene and protein expression observed in invasive tumours are already present in the transition from normal tissue to DCIS lesions.

\section{Conclusion}

We demonstrate here that gene expression profiling can distinguish between in situ breast cancer samples of well-versus poorly differentiated type. There appear to be a group of poorly differentiated samples, a group of well- and well-intermediately differentiated samples, and a third group containing mainly intermediately-poorly differentiated in situ cases. The quantitative differences in gene expression between these groups are mainly between twofold and fourfold. These differences are difficult to detect by classical IHC, because this technique is not very accurate in the quantification of small differences in protein expression. So far, there are no single markers that distinguish between the different types of DCIS, but the possibility of identifying a manageable panel of markers to distinguish the different types of DCIS lesions has to be further investigated.

\section{Competing interests}

The authors declare that they have no competing interests.

\section{Authors' contributions}

$\mathrm{JH}$ performed data analyses, participated in the study design, and drafted the manuscript. AV participated in data analyses. JBGH and BK carried out microarray hybridisations. JP and MV reviewed the histological specimens. MV participated in designing the study and drafting the manuscript. All authors read and approved the final manuscript. 


\section{Acknowledgements}

We thank N. Nasr for help in collecting pathology data and performing microarray hybridisations. This work was supported by the Dutch Cancer Society (02-2575).

\section{References}

1. Ernster VL, Ballard-Barbash R, Barlow WE, Zheng Y, Weaver DL, Cutter G, Yankaskas BC, Rosenberg R, Carney PA, Kerlikowske K, et al.: Detection of ductal carcinoma in situ in women undergoing screening mammography. J Natl Cancer Inst 2002, 94:1546-1554.

2. Pinder SE, Ellis IO: The diagnosis and management of pre-invasive breast disease: ductal carcinoma in situ (DCIS) and atypical ductal hyperplasia (ADH) - current definitions and classification. Breast Cancer Res 2003, 5:254-257.

3. Sneige N, Lagios MD, Schwarting R, Colburn W, Atkinson E, Weber D, Sahin A, Kemp B, Hoque A, Risin S, et al.: Interobserver reproducibility of the Lagios nuclear grading system for ductal carcinoma in situ. Hum Pathol 1999, 30:257-262.

4. Lakhani SR: The transition from hyperplasia to invasive carcinoma of the breast. J Pathol 1999, 187:272-278.

5. Buerger $\mathrm{H}$, Otterbach $F$, Simon R, Poremba C, Diallo R, Decker $T$, Riethdorf L, Brinkschmidt C, Dockhorn-Dworniczak B, Boecker W: Comparative genomic hybridization of ductal carcinoma in situ of the breast-evidence of multiple genetic pathways. J Pathol 1999, 187:396-402.

6. Vos CB, ter Haar NT, Rosenberg C, Peterse JL, Cleton-Jansen AM, Cornelisse CJ, van de Vijver MJ: Genetic alterations on chromosome 16 and 17 are important features of ductal carcinoma in situ of the breast and are associated with histologic type. $\mathrm{Br} J$ Cancer 1999, 81:1410-1418.

7. van de Vijver MJ, Peterse JL, Mooi WJ, Wisman P, Lomans J, Dalesio $\mathrm{O}$, Nusse R: Neu-protein overexpression in breast cancer. Association with comedo-type ductal carcinoma in situ and limited prognostic value in stage II breast cancer. N Engl J Med 1988, 319:1239-1245.

8. Simpson JF, Quan DE, O'Malley F, Odom-Maryon T, Clarke PE: Amplification of CCND1 and expression of its protein product, cyclin D1, in ductal carcinoma in situ of the breast. Am J Pathol 1997, 151:161-168.

9. Vos CB, Cleton-Jansen AM, Berx G, de Leeuw WJ, ter Haar NT, van Roy F, Cornelisse CJ, Peterse JL, van de Vijver MJ: E-cadherin inactivation in lobular carcinoma in situ of the breast: an early event in tumorigenesis. Br J Cancer 1997, 76:1131-1133.

10. Reis-Filho JS, Lakhani SR: The diagnosis and management of pre-invasive breast disease: genetic alterations in pre-invasive lesions. Breast Cancer Res 2003, 5:313-319.

11. Allred DC, Mohsin SK, Fuqua SA: Histological and biological evolution of human premalignant breast disease. Endocr Relat Cancer 2001, 8:47-61.

12. Perou CM, Sorlie T, Eisen MB, van de Rijn M, Jeffrey SS, Rees CA, Pollack JR, Ross DT, Johnsen H, Akslen LA, et al.: Molecular portraits of human breast tumours. Nature 2000 406:747-752.

13. Sorlie T, Perou CM, Tibshirani R, Aas T, Geisler S, Johnsen H, Hastie T, Eisen MB, van de Rijn M, Jeffrey SS, et al:: Gene expression patterns of breast carcinomas distinguish tumor subclasses with clinical implications. Proc Natl Acad Sci USA 2001, 98:10869-10874

14. Sorlie T, Tibshirani R, Parker J, Hastie T, Marron JS, Nobel A, Deng $\mathrm{S}$, Johnsen $\mathrm{H}$, Pesich R, Geisler S, et al.: Repeated observation of breast tumor subtypes in independent gene expression data sets. Proc Natl Acad Sci USA 2003, 100:8418-8423.

15. Sotiriou C, Neo SY, McShane LM, Korn EL, Long PM, Jazaeri A, Martiat $P$, Fox SB, Harris AL, Liu ET: Breast cancer classification and prognosis based on gene expression profiles from a population-based study. Proc Natl Acad Sci USA 2003, 100:10393-10398.

16. van 't Veer LJ, Dai $H$, van de Vijver MJ, He YD, Hart AA, Mao M, Peterse HL, van der Kooy K, Marton MJ, Witteveen AT, et al.: Gene expression profiling predicts clinical outcome of breast cancer. Nature 2002, 415:530-536.

17. Huang $E$, Cheng SH, Dressman H, Pittman J, Tsou MH, Horng CF, Bild A, Iversen ES, Liao M, Chen CM, et al:: Gene expression predictors of breast cancer outcomes. Lancet 2003, 361:1590-1596.
18. Wang $Y$, Klijn JG, Zhang $Y$, Sieuwerts AM, Look MP, Yang $F$, Talantov D, Timmermans M, Meijer-van Gelder ME, Yu J, et al: Gene-expression profiles to predict distant metastasis of lymph-node-negative primary breast cancer. Lancet 2005, 365:671-679.

19. Adeyinka A, Emberley E, Niu Y, Snell L, Murphy LC, Sowter H, Wykoff CC, Harris AL, Watson PH: Analysis of gene expression in ductal carcinoma in situ of the breast. Clin Cancer Res 2002. 8:3788-3795.

20. Seth A, Kitching R, Landberg G, Xu J, Zubovits J, Burger AM: Gene expression profiling of ductal carcinomas in situ and invasive breast tumors. Anticancer Res 2003, 23:2043-2051.

21. Holland R, Peterse JL, Millis RR, Eusebi V, Faverly D, van de Vijver MJ, Zafrani B: Ductal carcinoma in situ: a proposal for a new classification. Semin Diagn Pathol 1994, 11:167-180.

22. Elston EW, Ellis IO: Method for grading breast cancer. J Clin Pathol 1993, 46:189-190.

23. Weigelt B, Glas AM, Wessels LF, Witteveen AT, Peterse JL, van't Veer LJ: Gene expression profiles of primary breast tumors maintained in distant metastases. Proc Natl Acad Sci USA 2003, 100:15901-15905.

24. Supplementary information: classification of ductal carcinoma in situ by gene expression profiling [http://microarrays.nki.nl/ research/hannemann DCIS 2005/]

25. Hannemann J, Oosterkamp HM, Bosch CA, Velds A, Wessels LF Loo C, Rutgers EJ, Rodenhuis S, van de Vijver MJ: Changes in gene expression associated with response to neoadjuvant chemotherapy in breast cancer. J Clin Oncol 2005, 23:3331-3342.

26. Central Microarray Facility of the Netherlands Cancer Institute [http://microarray.nki.nl]

27. Software projects at the Institute for Genomics and Bioinformatics, TU Graz (Austria) [http://genome.tugraz.at/Software/]

28. Sturn A, Quackenbush J, Trajanoski Z: Genesis: cluster analysis of microarray data. Bioinformatics 2002, 18:207-208.

29. Khan J, Wei JS, Ringner M, Saal LH, Ladanyi M, Westermann F, Berthold F, Schwab M, Antonescu CR, Peterson C, et al.: Classification and diagnostic prediction of cancers using gene expression profiling and artificial neural networks. Nat Med 2001, 7:673-679.

30. Simon R, Radmacher MD, Dobbin K, McShane LM: Pitfalls in the use of DNA microarray data for diagnostic and prognostic classification. I Natl Cancer Inst 2003, 95:14-18.

31. Atasoy $\mathrm{P}$, Bozdogan $\mathrm{O}$, Ozturk S, Ensari A: Bcl2 expression and its correlation with neuroendocrine differentiation in colon carcinomas. Tumori 2004, 90:233-238.

32. Park SH, Kim H, Song BJ: Down regulation of bcl2 expression in invasive ductal carcinomas is both estrogen- and progesterone-receptor dependent and associated with poor prognostic factors. Pathol Oncol Res 2002, 8:26-30.

33. Ma XJ, Salunga R, Tuggle JT, Gaudet J, Enright E, McQuary P, Payette T, Pistone M, Stecker K, Zhang BM, et al.: Gene expression profiles of human breast cancer progression. Proc Natl Acad Sci USA 2003, 100:5974-5979.

34. Schuetz CS, Bonin M, Clare SE, Nieselt K, Sotlar K, Walter M, Fehm T, Solomayer E, Riess O, Wallwiener D, et al:: Progressionspecific genes identified by expression profiling of matched ductal carcinomas in situ and invasive breast tumors, combining laser capture microdissection and oligonucleotide microarray analysis. Cancer Res 2006, 66:5278-5286.

35. Paik S, Shak S, Tang G, Kim C, Baker J, Cronin M, Baehner FL, Walker MG, Watson D, Park T, et al:: A multigene assay to predict recurrence of tamoxifen-treated, node-negative breast cancer. N Engl J Med 2004, 351:2817-2826.

36. Zemzoum I, Kates RE, Ross JS, Dettmar P, Dutta M, Henrichs C, Yurdseven S, Hofler H, Kiechle M, Schmitt M, et al.: Invasion factors uPA/PAI-1 and HER2 status provide independent and complementary information on patient outcome in node-negative breast cancer. J Clin Oncol 2003, 21:1022-1028.

37. Goodman JD, Rozypal TL, Kelly T: Seprase, a membrane-bound protease, alleviates the serum growth requirement of human breast cancer cells. Clin Exp Metastasis 2003, 20:459-470.

38. Allinen M, Beroukhim R, Cai L, Brennan C, Lahti-Domenici J, Huang H, Porter D, Hu M, Chin L, Richardson A, et al.: Molecular characterization of the tumor microenvironment in breast cancer. Cancer Cell 2004, 6:17-32. 
39. Nagaraja GM, Othman M, Fox BP, Alsaber R, Pellegrino CM, Zeng Y, Khanna R, Tamburini P, Swaroop A, Kandpal RP: Gene expression signatures and biomarkers of noninvasive and invasive breast cancer cells: comprehensive profiles by representational difference analysis, microarrays and proteomics. Oncogene 2006, 25:2328-2338.

40. Porter D, Lahti-Domenici J, Keshaviah A, Bae YK, Argani P, Marks J, Richardson A, Cooper A, Strausberg R, Riggins GJ, et al.: Molecular markers in ductal carcinoma in situ of the breast. Mol Cancer Res 2003, 1:362-375.

41. Wulfkuhle JD, Sgroi DC, Krutzsch H, McLean K, McGarvey K Knowlton M, Chen S, Shu H, Sahin A, Kurek R, et al.: Proteomics of human breast ductal carcinoma in situ. Cancer Res 2002, 62:6740-6749. 